1 Harjai, KJ, Licata, AA. Effects of amiodarone on thyroid function. Ann Intern Med 1997;126:63-73.

Fradkin JE, Wolff J. Iodine-induced thyrotoxicosis. Medicine 1983;62:1-20.

3 Aanderud S, Sundsfjord J, Aarbakke J. Amiodarone inhibits the conversion of thyroxine to triiodothyronine in isolated rat hepatocytes. Endocrinology 1984;115:1605-8.
4 Albert SG, Alves LE, Rose EP. Thyroid dysfunction during chronic amiodarone therapy. F Am Coll Cardiol 1987;9:17583.

5 Martino E, Aghini-Lombardi F, Mariotti S, Bartalena L, Baverman L, Pinchera A. Amiodarone: a common source of iodine-induced thyrotoxicosis. Horm Res 1987;26:158-71.

\title{
A case of intestinal obstruction
}

\author{
N P Michell, H Routledge, I M Chesner
}

A 66-year-old woman was referred with a 2-month history of increasing abdominal pains which were central, colicky and associated with abdominal distension. Her symptoms were worse after food. Over this period she had also developed loose stools 2-3 times per day. She denied weight loss. Medical history included psoriasis complicated by a small joint arthropathy. There had been no previous abdominal surgery and she was taking prescribed slow-release diclofenac and sulphasalazine. On examination she was anaemic with a psoriatic rash on her elbows and shins. The distal interphalangeal joints were deformed. The abdomen was distended, more so on the right, but there were no palpable masses or organomegaly. Bowel sounds were normal. Investigations revealed an iron deficiency anaemia (haemoglobin $8.6 \mathrm{~g} / \mathrm{dl}$ ) and low serum albumin (29 $\mathrm{g} / \mathrm{dl}$ ). Other tests of liver function were normal as were inflammatory markers. An upper gastrointestinal endoscopy and duodenal biopsies were normal. A colonoscopy was performed and three strictures were found in the transverse colon, the most proximal of which could not be passed (figure).

Department of Gastroenterology, Birmingham Heartlands Hospital NHS Trust, Bordesley Green, Birmingham B9 5SS, UK

N P Michell

H Routledge

I M Chesner

Submitted 23 April 1999 Accepted 14 June 1999

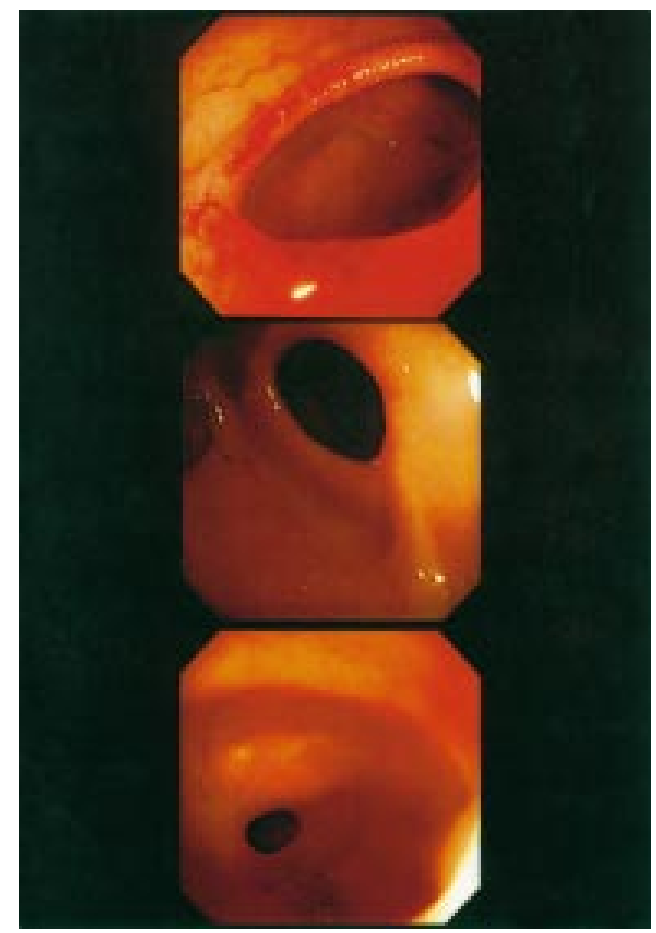

Figure Colonoscopic appearances of the ascending colon.

\section{Questions}

1 What do the pictures taken at colonoscopy show?

2 What is the likely aetiology of such lesions?

3 What gastrointestinal diseases are associated with psoriasis? 


\section{Answers}

QUESTION 1

The figures show smooth diaphragm-like strictures with linear ulceration of the inner rim.

QUESTION 2

These lesions are characteristically associated with non-steroidal anti-inflammatory drugs (NSAIDs).

QUESTION 3

Patients with Crohn's disease, and their first degree relatives, are more likely to develop psoriasis suggesting a genetic link. HLA B13, Bw58, Cw6 and DR7 are over-represented in both psoriasis and Crohn's disease. To a lesser extent, ulcerative colitis is associated with psoriasis.

\section{Discussion}

NSAIDs are a well known cause of intestinal ulceration, inflammation and haemorrhage. The commonest clinical side-effects occur in the stomach and duodenum but, in postmortem studies, damage is most frequently observed in the small bowel. ${ }^{1}$ NSAID enteropathy is usually asymptomatic but may result in hypoalbuminaemia and iron deficiency anaemia, which can be severe and refractory to oral supplementation. Rarely, such small bowel ulcers may heal by fibrosis with expansion of the submucosa myocytes resulting in thin diaphragm-like strictures. Such strictures pre-

Allison MC, Howatson AG, Torrance CJ, Lee FD, Russell RI. Gastrointestinal damage associated with the use of nonsteroidal anti-inf

2 Lang JM, Price AB, Levi AJ, Burke M, Gumpel JM, Bjarnason I. Diaphragm disease: pathology of disease of the small intestine induced by non-steroidal anti-inflammatory drugs. f Clin Pathol 1988;41:516-26.

3 Going JJ, Canvin J, Sturrock R. Possible precursor of diaphragm disease of the small intestine. Lancet 1993;341: 638-9. dominate in the small bowel, but have been reported in the right colon in association with slow-release NSAID formulations. ${ }^{2}{ }^{3}$ These observations, and the similarity between NSAID and potassium-induced strictures, suggest a local effect. However, there have been reports of diaphragms complicating rectal indomethacin in the absence of oral preparations. ${ }^{4}$ In such cases mucosal injury may be mediated via the systemic effects of NSAIDs on prostaglandin synthesis which results in increased mucosal permeability and translocation of luminal contents. The consequent inflammation is compounded by impaired repair mechanisms.

Clinical presentation of NSAID enteropathy varies from vague abdominal pains to symptoms of subacute obstruction as mucosal inflammation and ulceration repair with stricture formation. ${ }^{5}$ In the absence of symptomatic strictures, NSAID enteropathy has successfully been treated with metronidazole, sulphasalazine, 5-aminosalicylates and misoprostol. Symptomatic strictures require surgical resection. In this case symptoms resolved entirely on a low residue diet and cessation of diclofenac (sulphasalazine was continued).

\section{Final diagnosis}

NSAID-induced strictures in the transverse colon.

Keywords: non-steroidal anti-inflammatory drugs; intestinal obstruction; adverse drug reaction

4 Hooker GD, Gregor JC, Ponich TP, McLarty TD. Diaphragm-like strictures of the right colon induced by indomethacin suppositories; evidence of a systemic effect. Gastrointest Endosc 1996;44:199-202.

5 Bjarnason I, Price AB, Zanelli G, et al. Clinicopathological features of non-steroidal anti-inflammatory drug-induced small intestine strictures. Gastroenterology 1988;94:516-26. 


\title{
Isosexual precocity: uncommon presentation of a common disorder
}

\author{
A Bhansali, A Kashyap, S Lodha, N Kotwal, B Ganapathi, B R Mittal, R J Dash
}

A 7-year-old girl presented with bilateral symmetrical enlargement of breasts of one year duration and one episode of vaginal bleed in August 1996. She did not have history of seizure disorder, meningitic or encephalitic illness, head injury or administration of oestrogen-containing preparations. She was an active child and had good scholastic performance.

On examination, her height was $108 \mathrm{~cm}$ (<3rd centile), weight $21 \mathrm{~kg}(10-25$ th centile) and bone age was 3 years. Her pubertal status (Tanner) was $\mathrm{B}_{3} \mathrm{~A}_{1} \mathrm{P}_{1}$ (figure 1 ). She had no goitre and her deep tendon reflexes showed delayed relaxation.

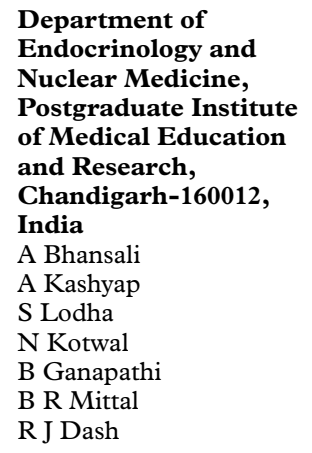

Submitted 29 April 1999 Accepted 14 May 1999

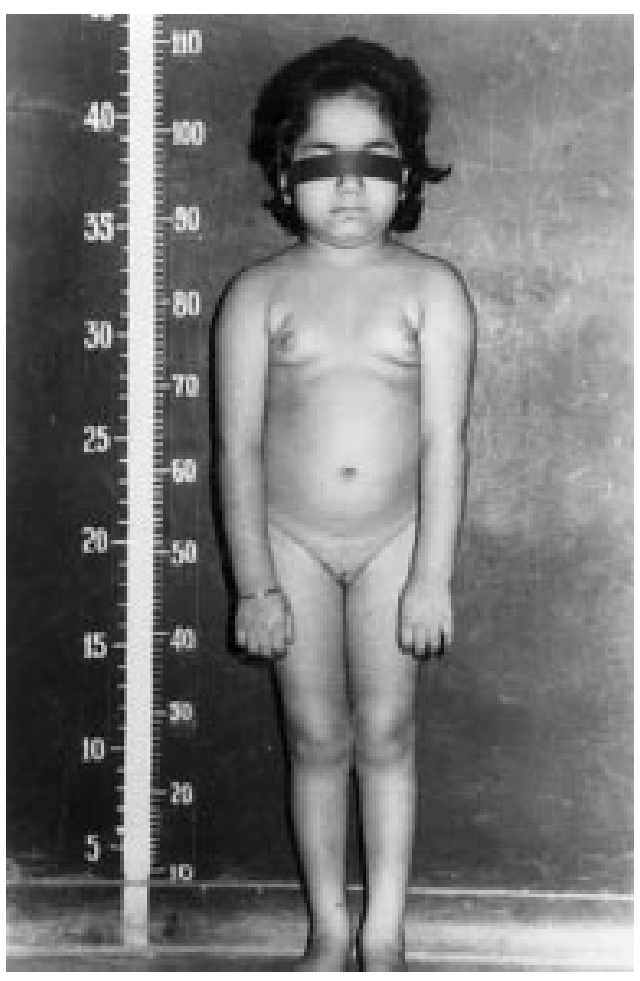

Figure 1 Photograph showing short child with premature breast enlargement (reproduced with the parents' permission)

\section{Questions}

1 What is the diagnosis?

2 What investigations would you perform next?

3 How would you treat this case? 